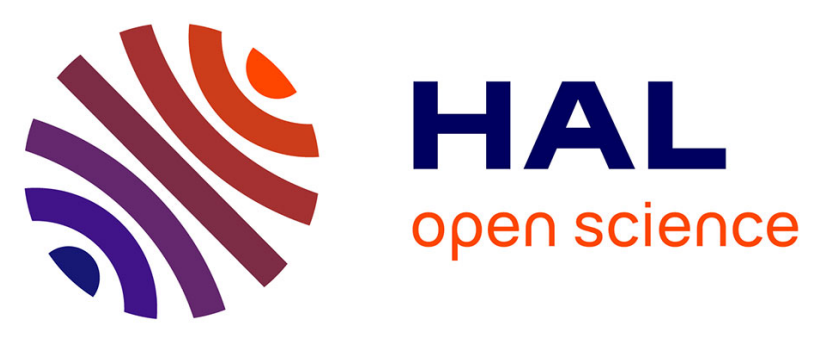

\title{
Minimizing the risk of exercise-induced glucose fluctuations in people living with type 1 diabetes using continuous subcutaneous insulin infusion: an overview of strategies
}

Joséphine Molveau, Rémi Rabasa-Lhoret, Nadine Taleb, Elsa Heyman, Etienne Myette Coté, Corinne Suppère, Serge Berthoin, Sémah Tagougui

\section{To cite this version:}

Joséphine Molveau, Rémi Rabasa-Lhoret, Nadine Taleb, Elsa Heyman, Etienne Myette Coté, et al.. Minimizing the risk of exercise-induced glucose fluctuations in people living with type 1 diabetes using continuous subcutaneous insulin infusion: an overview of strategies. Canadian Journal of Diabetes, 2021, Canadian Journal of Diabetes, 10.1016/j.jcjd.2021.01.003 . hal-03141199

\author{
HAL Id: hal-03141199 \\ https://hal.univ-lille.fr/hal-03141199
}

Submitted on 15 Feb 2021

HAL is a multi-disciplinary open access archive for the deposit and dissemination of scientific research documents, whether they are published or not. The documents may come from teaching and research institutions in France or abroad, or from public or private research centers.
L'archive ouverte pluridisciplinaire HAL, est destinée au dépôt et à la diffusion de documents scientifiques de niveau recherche, publiés ou non, émanant des établissements d'enseignement et de recherche français ou étrangers, des laboratoires publics ou privés. 
Molveau J, Rabasa-Lhoret R, Taleb N, Heyman E, Coté EM, Suppère C,Berthoin S, Tagougui S, Minimizing the risk of exercise-induced glucose fluctuations in people living withtype 1 diabetes using continuous subcutaneous insulin infusion: an overview of strategies, CanadianJournal of Diabetes (2021), doi: https://doi.org/10.1016/j.jcjd.2021.01.003

Minimizing the risk of exercise-induced glucose fluctuations in people living with type 1 diabetes using continuous subcutaneous insulin infusion: an overview of strategies

Authors: Joséphine Molveau ${ }^{1}$, Rémi Rabasa-Lhoret ${ }^{1,2,3,4,5}$, Nadine Taleb $^{1,3}$, Elsa Heyman ${ }^{6}$, Etienne Myette Coté ${ }^{1,7}$, Corinne Suppère ${ }^{1}$, Serge Berthoin ${ }^{6}$, Sémah Tagougui ${ }^{1,2,6}$.

ST and RRL contributed equally to this work.

Affiliations :

${ }^{1}$ Institut de recherches cliniques de Montréal, Montréal, Québec, Canada.

${ }^{2}$ Département de Nutrition, Faculté de Médicine, Université de Montréal, Montreal, QC, Canada

${ }^{3}$ Département des Sciences Biomédicales, Faculté de Médicine, Université de Montréal, Montreal, QC, Canada

${ }^{4}$ Division of Endocrinology, McGill University, Montreal, QC, Canada

${ }^{5}$ Endocrinology Division, Montreal Diabetes Research Center, Montreal, QC, Canada

${ }^{6}$ Univ. Lille, Univ. Artois, Univ. Littoral Côte d’Opale, ULR 7369 - URePSSS - Unité de Recherche Pluridisciplinaire Sport Santé Société, F-59000 Lille, France

${ }^{7}$ Department of Medicine, McGill University, Montreal, Quebec, Canada

Correspondance:

Dr. Sémah Tagougui

semah.tagougui@univ-lille.fr

Pr. Rémi Rabasa-Lhoret

remi.rabasa-Ihoret@ircm.qc.ca

Word count: 4548 (Main text), and 201 (Abstract), 2 tables, 2 figures 
Résumé : Physical activity (PA) is important for individuals living with type 1 diabetes (T1D) due to its various health benefits. Nonetheless, maintaining adequate glycemic control around PA remains a challenge for many individuals living with T1D because of the difficulty to properly manage circulating insulin levels around PA. While the most common problem is increased incidence of hypoglycemia during and after most types of PA, hyperglycemia can also occur. Accordingly, a large proportion of people living with T1D are sedentary partly due to the fear of PA-associated hypoglycemia. Continuous subcutaneous insulin infusion (CSII) offers a higher precision and flexibility to adjust insulin basal rates and boluses according to the individual's specific needs around PA practice. Indeed, for physically active patients with T1D, CSII can be a preferred option to facilitate glucose regulation. To our knowledge, there are no guidelines to manage exercise-induced hypoglycemia during PA, specifically for individuals living with T1D and using CSII. This review highlights the current state of knowledge on exercise-related glucose variations, especially the hypoglycemic risk as well as its underlying physiology. Further, we detail the current recommendations for insulin modulations according to the different PA modalities (type, intensity, duration, frequency) in individuals living with T1D using CSII.

Keywords: CSII, insulin pump, physical activity, exercise, hypoglycemia, hyperglycemia, type 1 diabetes 


\section{Introduction}

Type 1 diabetes (T1D) is a chronic condition caused by the autoimmune destruction of the insulin producing pancreatic beta cells that requires life-long insulin replacement treatment therapy. Intensive insulin therapy can be implemented using multiple daily injections (MDI) or continuous subcutaneous insulin infusion (CSII) also known as insulin pump therapy (1). CSII provides increased flexibility for insulin dosing and is becoming an increasingly popular option among people living with T1D. Nonetheless, this method presents certain drawbacks including higher costs, technological issues such as catheter replacements, and pump visibility $(2,3)$. In contrast to the fixed rates delivered by long-acting insulin pens/syringes, the basal rate insulin infusion with CSII can be frequently adjusted throughout the day according to individual's needs and activity levels. Thus, as physical activity (PA) is associated with rapid changes for insulin needs, this CSII feature is of particular interest for active people living with T1D, including children and adolescents.

Regular PA is highly recommended as it can contribute to meet key therapeutic objectives in T1D including the reduction of chronic hyperglycemia and hypoglycemic events (4). Moreover, by improving insulin sensitivity, physical fitness, endothelial function, body composition and lipid levels, PA can be effective at limiting diabetes-related complications (5). Regular PA is also associated with psychosocial benefits such as overall well-being, improved quality of life and decreased stress and anxiety (6). However, despite these benefits, over $60 \%$ of individuals living with T1D are not meeting the current PA guidelines (7,8) mainly because of the fear of hypoglycemia and difficulty to maintain optimal glucose control during and after PA (9). In addition to the absence of endogenous insulin secretion, individuals with T1D also experience other endocrine disturbances such as dysregulated secretion of counterregulatory hormones (e.g., glucagon and epinephrine) putting them at very high risk of PA-associated glucose fluctuations, especially hypoglycemic episodes (10). Previously, MacDonald et al. (11) showed that the risk of PA-associated hypoglycemia remains elevated for up to 31-h after exercise. Over that period, insulin sensitivity is increased and some counterregulatory mechanisms are blunted which together limit the metabolic defenses against hypoglycemia (12). The fact that blood glucose responses vary depending on the type, intensity, timing, and duration of PA, largely explain the difficulty of people living with T1D to predict and avoid extreme glucose fluctuations (13).

So far, the most common strategies to improve glucose control during and after PA has been focused on modulating insulin injection and carbohydrate $(\mathrm{CHO})$ intake around PA sessions. With aerobic PA, patients usually require less insulin (basal and/or meal insulin) and/or additional $\mathrm{CHO}$ intake, while for moderate to high intensity anaerobic PA, small extra doses of insulin might be necessary with or without the addition of $\mathrm{CHO}(14)$. Indeed, continuous aerobic moderate-intensity (MOD) exercise (e.g. running, swimming, cycling) is known to induce progressive blood glucose lowering, whereas anaerobic PA (e.g., resistance training, gymnastics) or mixed activities (e.g., high-intensity intermittent exercise 'HIE': Tennis, basketball, 
volleyball) are often associated with a higher risk of hyperglycemia during exercise (14-18) (figure 2). In addition to the risk of hyperglycemia during mixed and anaerobic activities, hypoglycemia can occur during recovery when exercise is performed in the post-absorptive state (19). In the hours following a PA session, glucose is diverted from the blood to restore hepatic and muscle glycogen content, putting individuals living with T1D at higher risk of hypoglycemia. Additionally, if the PA session is performed in the evening, this transition period where the risk of hypoglycemia is increased will frequently occur overnight at a time when hypoglycemic detection is altered (20).

For individuals living with T1D who want to participate in regular PA, several factors starting ahead of PA and extending largely after need to be considered, which can easily become tedious and discourage them from staying active.

The current review aims to summarize the available literature on PA for CSII users with a focus on 1) the key factors implicated in PA-associated glucose fluctuations and 2) the available strategies to minimize PA-associated glucose fluctuations depending on the chosen type, intensity, duration and timing of PA.

\section{Mechanisms of PA-induced glycemic dysregulations in T1D}

PA represents a physiological stressor that disrupts glucose homeostasis and energy needs according to its type and modalities. During PA, glucose utilization from the circulation and glycogen stores is upregulated to meet the energy demand of the working muscles (15). In addition, the metabolic benefits expand largely beyond the PA period as the muscles will replenish their glycogen stores and insulin sensitivity will be improved for several hours.

In individuals without T1D, the secretion of insulin during most types of PA is rapidly suppressed while that of glucose counterregulatory hormones (e.g., glucagon, catecholamines, growth hormone and cortisol) is increased allowing hepatic glucose production to match the elevated muscle glucose disposal rate and minimize glucose fluctuations (21). In individuals with T1D, the inability to reduce circulating insulin levels once insulin has been administrated along with defective counterregulatory hormones responses in conditions of glucose lowering greatly increase the risks of hypoglycemia during and after PA. In some instances of very high intensity PA, counterregulatory hormones have been shown to induce hyperglycemia while endogenous insulin secretion is not possible (22). Since all types of PA enhance insulin sensitivity for 12-18 hours, the risk of hypoglycemia extends to the following overnight hours (14). The underlying mechanisms of PA-induced hypoglycemia are well understood $(10,23)$. In individuals without T1D, several physiological adaptations occur during PA including increase in blood flow, insulin and glucose delivery to skeletal muscle. Moreover, muscle contractions enhance insulin receptor 
sensitivity and stimulate glucose-transporter 4 (GLUT-4) translocation both translating into glucose uptake upregulation (24). In addition, PA and/or stress (e.g., competition) increase the sympathetic nervous activity which has an inhibitory effect on

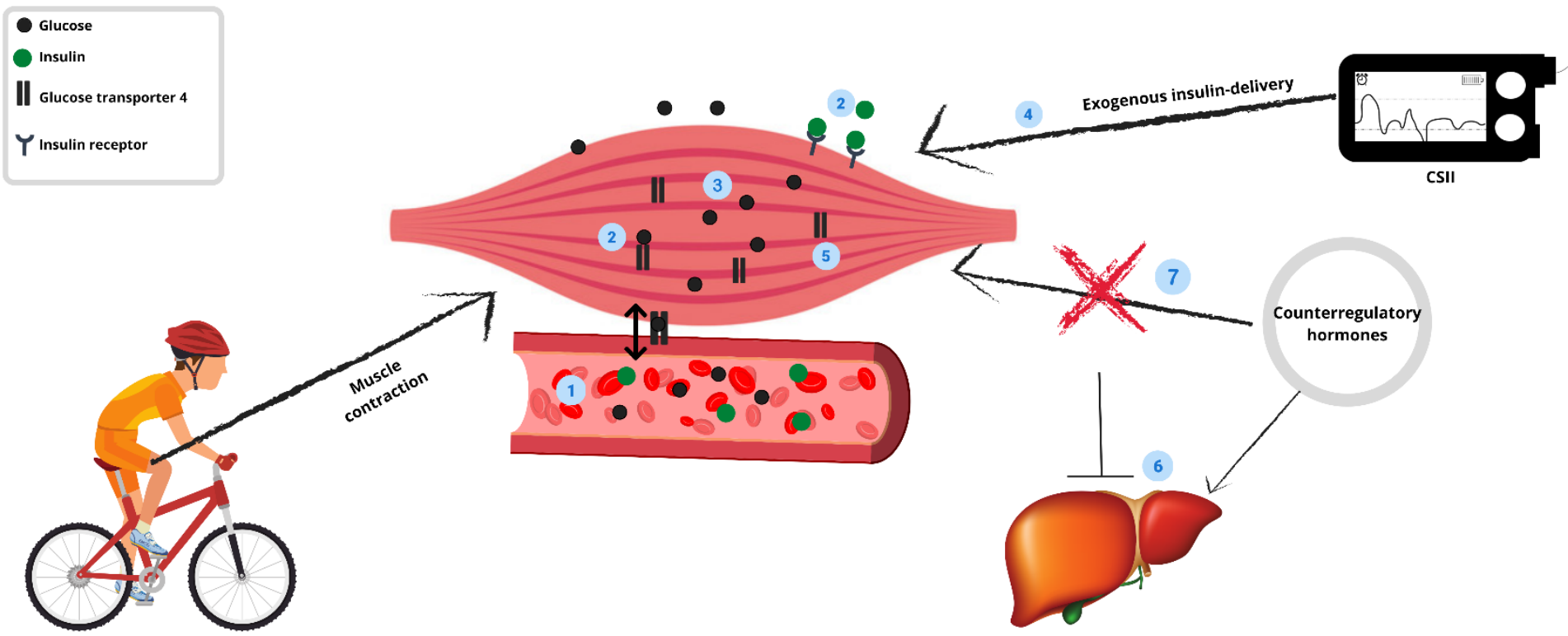

insulin secretion and stimulates hepatic glucose production limiting the risk of hypoglycemia (25). A key regulator of all these mechanisms is the ability of individuals without T1D to rapidly reduce endogenous insulin secretion after PA onset (26).

Conversely, in people living with T1D, without anticipated action, exogenous insulin is not reduced with PA and glucose utilization is further increased while hepatic glucose production is inhibited, resulting in a rapid glucose decrease (27). In addition, counterregulatory hormones regulation is frequently altered in individuals with T1D while the remaining counterregulatory hormone regulation is both inhibited and can be largely insufficient in a context of relative or absolute hyperinsulinemia (28). Some of these abnormalities are further exacerbated by PA as low-moderate intensity exercise causes a significantly blunted increase in epinephrine, lipolysis and other factors that constitute the adrenergic response generated by a hypoglycemic episode (29). Finally, during PA, increased blood circulation favours the subcutaneous absorption of insulin which can thus increase, further exacerbating the risk of hypoglycemia (14) (figure 1).

Figure 1 Mechanisms of glycemic dysregulation during exercise: (1) Increased blood flow (2) Enhanced Insulin sensitivity and glucose transporter 4 translocation by muscle contraction (3) Upregulated glucose uptake (4) Possibly high levels of circulating insulin if lowering basal insulin delivery is not applied before and/or during PA (5) further increase of glucose utilization (6) inhibited hepatic glucose production resulting in a rapid glucose decrease (7) altered counterregulatory response while the remaining counterregulatory response is both inhibited and can be largely insufficient in a context of relative or absolute hyperinsulinemia. 
As reported by Diabetes Canada (30), PA are often classified into two major types, each displaying specific effects on blood glucose levels (figure 2) :

(continuous low-to-moderate intensity exercise, e.g., jogging, running, swimming, cycling, etc. and HIE PA). In the current review we will refer to this type of exercise as 'aerobic' for simplicity, even though when achieved at a very high intensity, such as with HIE PA, it also includes some anaerobic PA.

2) Anaerobic PA (e.g., resistance exercise, sprint, etc.). However, most activities rely on the interplay between both aerobic and anaerobic PA (e.g., mixed activities). 


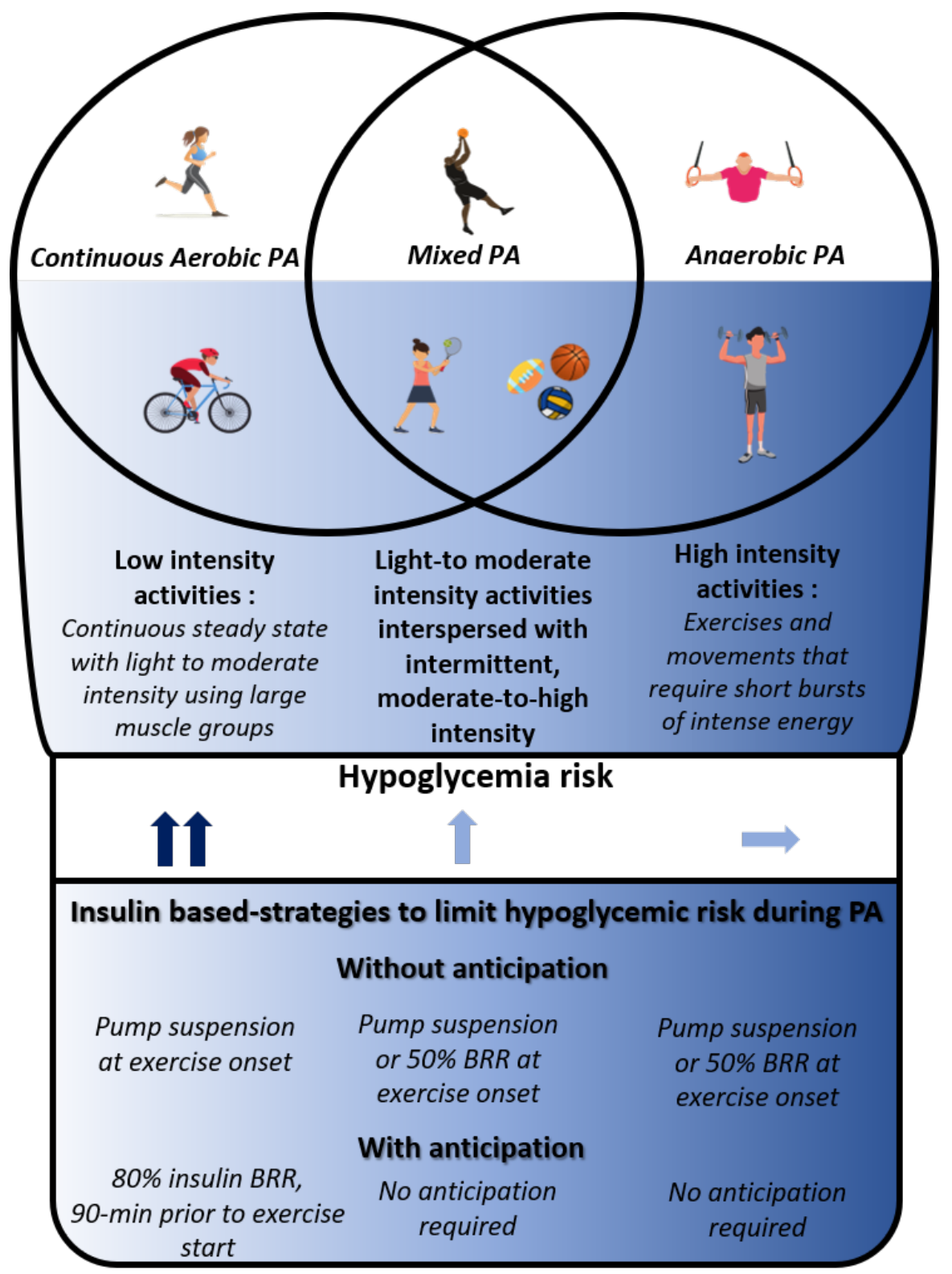

*Physical activities (PA)

*Insulin basal rate reduction (BRR)

* Figure created using published data from: Zaharieva et al.

2019, Zaharieva et al. 2020 and Riddel et al. 2017

Figure 2 Organigram describing the hypoglycemic risk depending on the type and intensity of PA

PA can also be classified as post-prandial when performed within 2-3 hours following a meal or post-absorptive otherwise. During the post-prandial period, monosaccharides are absorbed and released into the bloodstream followed by the post-absorptive period during which glucose levels are maintained through hepatic gluconeogenesis and glycogenolysis. A good understanding of the physiological effects associated with the different types of PA is important in order to choose the optimal strategy to regulate blood glucose levels around PA in individuals with T1D using CSII. 
Low-to-moderate intensity continuous PA remains the most practiced type of PA by individuals with T1D and is associated with an increased risk of PA-induced hypoglycemia during and for up to 11-h after PA (31). Riddell et al. (32) reported that when no strategy was applied to minimize the drop in blood glucose levels, the incidence of exercise-induced hypoglycemia reached $\sim 44 \%$. Their research also indicated that higher blood glucose levels at the onset of exercise were associated with greater glucose reduction during and after exercise but resulted in less hypoglycemic events overall, a finding that has not been observed in another study (33).

High intensity PA ( $\mathbf{7 5 \%}$ of $\mathbf{V O}_{2 \max }$ ) and anaerobic PA are usually associated with a lesser drop in blood glucose levels due to a higher release in catecholamines and glucose from the liver that can meet or even exceed muscle glucose's need $(34,35)$. Though the counterregulatory hormonal response is frequently defective in individuals living with T1D performing lowto-moderate intensity PA, it is usually preserved during high intensity sessions (36). Indeed, glucose production will increase up to eight fold and glucose utilization will increase up to three fold $(37,38)$. In individuals without T1D, insulin levels following exercise will increase to restore euglycemia. However, in individuals with T1D, the inability to increase insulin levels endogenously can induce prolonged hyperglycemia (38) if there is no insulin administration. Such scenarios do not protect from late-onset hypoglycemia as muscle glucose utilization also remains elevated in subsequent hours (35).

Intermittent high intensity PA (HIE) consists of continuous moderate intensity PA interspersed with short bouts of very intense effort ( $\geq 85 \%$ of $\mathrm{VO}_{2 \max }$ ). During $\mathrm{HIE}$, the drop in blood glucose levels induced by moderate intensity PA is limited by the stimulation of counterregulatory hormone secretion (39).

Thus, in people living with T1D, six key factors modulate glucose fluctuations during PA:

1. The type of PA with moderate intensity aerobic exercise mainly increasing hypoglycemic risk during PA and anaerobic exercise or high intensity aerobic exercise inducing hyperglycemia during PA. Both types of PA are associated with an increased risk of late-onset hypoglycemia.

2. The duration of PA as the body becomes more dependent on plasma glucose with prolonged PA (>60-min) (40).

3. The intensity of PA as it impacts the balance between muscle glucose utilization and hepatic glucose production in response to some counterregulatory hormones.

4. The timing of PA during the day and the consumption of the last meal prior to PA also need to be considered since they have a major impact on the availability of glucose from the gut and active insulin from the last bolus.

5. Blood glucose levels at PA onset can have a buffering effect (e.g. close to $10.0 \mathrm{mmol} / \mathrm{L}$ ) which will limit the risk of hypoglycemia during PA. Although, blood glucose levels should not be too high (e.g. > $15.0 \mathrm{mmol} / \mathrm{L}$ ), at the risk of reaching a critical point where active insulin becomes insufficient thus increasing the risk of hyperglycemia and ketosis.

6. Active or 'on-board' insulin must be taken into consideration prior to engaging in exercise. 


\section{Strategies to reduce the risk of PA-induced hypoglycemia}

Several strategies to prevent PA-induced hypoglycemia exist, but it is often difficult for individuals with T1D to determine which one is the most appropriate to apply depending on the type, duration, intensity, period of PA (e.g. postprandial or post-absorptive PA) and interindividual differences in responsiveness. Most studies have addressed aerobic PA, but where applicable, we will address other types of PA.

\section{$\underline{\text { PA without anticipation }}$}

In a pediatric population it was reported that as compared to continued CSII, suspending CSII at the start of a 75-min post-absorptive MOD, the frequency of hypoglycemic events was limited (16\%), but not eliminated (41). Other studies have compared significant basal rate reduction (BRR) to no change in CSII settings. Franc et al. (42) reported that reducing insulin basal rate by $80 \%$ at the beginning of a 30 min MOD session performed 3-h after the last meal and kept at such level for 2-h after PA also limited the risk of PA-induced hypoglycemia by 55\%. Admon et al. (43) found that a $50 \%$ BRR or CSII suspension at the beginning of a 40-min MOD session started 2-h after the last meal limited the risk of hypoglycemia as well. It was reported that with a $50 \%$ BRR 5-min prior to a $45-$ min $\mathrm{MOD}$ session ( $55 \% \mathrm{VO}_{2 \mathrm{max}}$ ), the time spent in hypoglycemia during and after PA was limited but not suppressed ( $10 \%$ and $8 \%$, respectively) as compared to glucose tablet ingestion ( $0 \%$ and $8 \%$, respectively) and mini dose glucagon ( $1 \%$ and $6 \%$, respectively) (44). One could speculate that with longer PA, these BRR might delay, but not reduce hypoglycemic risk. Indeed, among individuals living with T1D and exercising regularly, most PA sessions last 1 h or more (45) but data in such condition are currently lacking.

For unplanned PA, $\mathrm{CHO}$ supplementation before and/during PA is often one of the simplest solutions, but the modalities such as the optimal amount and timing of $\mathrm{CHO}$ intake have not been well studied. Thus, there is a risk of overcompensation with excessive $\mathrm{CHO}$ intake and rebound hyperglycemia, especially during intense PA and immediately after. $\mathrm{CHO}$ consumption could also contribute to undesired weight gain or limit weight loss attempts and possibly worsen individuals with T1D's glycated hemoglobin $\left(A 1_{c}\right)$ levels (46). Recommended amount of CHO intake for activities lasting from 30-60-min ranges widely from 10-15 g per hour of activity for athletes to 15-30 g per 30-min for recreational activities (14). However, the glucose threshold before or during PA at which $\mathrm{CHO}$ intake should be prescribed to prevent hypoglycemia can be a controversial point. While some studies have suggested that values above $7.0 \mathrm{mmol} / \mathrm{L}$ might be protective (14), a new position statement (47) reported that with a glucose threshold of $7.0 \mathrm{mmol} / \mathrm{L}$ associated with a horizontal trend arrow, 10-15 $\mathrm{g}$ of $\mathrm{CHO}$ should be consumed.

\section{$\underline{\text { PA with anticipation }}$}




\section{$\underline{\text { PA undertaken in the post-prandial period }}$}

Individuals using CSII have the option of reducing insulin basal rate delivery which allows a more precise insulin adjustment than with MDI regimens. Although this approach was extensively tested in post-absorptive period (see below: ' $\underline{P A}$ undertaken in the post-absorptive period') we are not aware of any studies that have investigated if reducing basal rate should be combined with a meal bolus reduction. Although, Franc et al. (42) have compared the effect of meal bolus reduction with insulin BRR and found a favorable trend for meal bolus reduction when MOD was undertaken within 90-min after the meal. However, this study did not aim to combine meal bolus and BRR strategies. Most studies have tested PA undertaken 90-min after a meal and to our knowledge no data is available to confirm if general guidelines about meal bolus reduction should be adapted if PA is undertaken earlier or later than 90-min after a meal. Reducing meal bolus is also an important option when exercise is performed in the post-prandial state for individuals with T1D using either MDI or CSII. For an MOD session starting 90-min after a meal, the proportion of the reduction should be adapted to the duration and intensity of PA (Table 1) (47). It should be noted that, though this meal-bolus reduction strategy allows to reduce pre-PA hypoglycemic risk, it can be associated with a post-PA hyperglycemic trend (47).

\section{$\underline{\text { PA undertaken in the post-absorptive period }}$}

Studies using CSII suspension or BRR at the start of PA failed to eliminate hypoglycemia $(41,43,48)$. Based on available rapid-acting insulin analog pharmacokinetics, anticipated BRR would be needed to reproduce the desired lower insulin levels at the time of PA. For practical reasons, the shorter the time needed to anticipate PA and modify CSII setting, the better. Thus, Roy Fleming et al. (33) found a trend toward fewer hypoglycemic events occurring late towards the end of the PA sessions when an $80 \%$ BRR was applied 40-min prior PA onset, suggesting that earlier time-points should be tested (table 2). McAuley et al. (49) investigated the effect of a $50 \%$ insulin BRR, 60-min prior to performing a 30-min moderate intensity cycling and found a protective effect when pre-exercise blood glucose was above $5.0 \mathrm{mmol} / \mathrm{L}$, but as mentioned above, the short duration of PA session might limit the applicability of this finding (table 2). Implementing BRR by 50 or $80 \%, 90-$ min prior to a 60 -min PA session starting 3-h after the last meal significantly reduced hypoglycemic risk compared to CSII suspension at PA onset (table 2) (16).

The downside of such prolonged insulin BRR is that it increases the risk of hyperglycemia before PA and even more in the immediate (1-2 hours) post-PA period (3). However, post-PA hyperglycemia tends to be lower in individuals using CSII compared to MDI (50). A recent proof of concept study suggested that for prolonged training, CSII basal rate could be partially replaced by a long-acting basal insulin Degludec. This would allow CSII suspension or disconnection 60 min before PA and 
reconnected immediately after PA. Using this approach could reduce post-PA hyperglycemia (51). Such an approach could be useful in situations where CSII cannot be used (e.g. prolonged swimming, scuba diving, martial arts, etc.).

Overall, when PA is unplanned, BRR can only be made at the start of PA and/or during the recovery period. In the context of continuous moderate intensity aerobic PA of 45-min or shorter, pump suspension at exercise onset seems to be the best strategy. Ideally, an $80 \%$ BRR should be set at least $60-90$ min before the onset of exercise to reduce circulating insulin levels given the pharmacokinetics of available insulin formulations. However, this type of BRR requires significant anticipation of PA and may not be feasible in many situations. These strategies can be combined with CHO intake.

\section{Strategies to reduce the risk of PA-induced hyperglycemia}

During high-intensity PA, individuals living with T1D can experience a rise in blood glucose levels. Therefore, for this type of PA, it would be suitable to propose less or no insulin BRR as compared to continuous moderate PA. It has been proposed in individuals living with T1D using CSII to reduce by 50\% their insulin basal rate 60 -min before PA onset (45-min of resistance exercise vs. $45-\mathrm{min}$ of $60 \% \mathrm{VO}_{2 \mathrm{max}}$ aerobic exercise) until the end of PA (13). Importantly, while glucose levels drop less during resistance than during aerobic continuous sessions, the risk of late-onset PA-induced hypoglycemia was two times higher after the resistance sessions (13). Although the risk of late-onset PA-related hypoglycemia is present, it was reported that performing resistance PA prior to aerobic PA significantly reduced glycemic variability throughout PA (52). Furthermore, Reddy et al. (53) suggested that acute resistance PA was more efficient than acute aerobic PA to improve overall glucose control in adults with T1D using CSII. Results indicated that the time spent within glycemic target range was improved by $14.6 \%$ after resistance PA and the time spent in hyperglycemia was also significantly reduced (-16\%) during the 24-h following the PA session (53). However, this study only investigated the acute effects of these PA sessions.

Another study reported that basal insulin suspension at the onset of PA led to a greater reduction in glycemia during continuous versus circuit-based PA suggesting that lower reduction could be appropriate for circuit-based sessions (table 2) (54). More recently, it was reported that during a 40-min HIE session, reducing basal rate by $50 \%$ or suspending insulin pump at PA onset were both effective methods to limit the risk of PA-induced hypoglycemia (17). However, insulin pump suspension during HIE have also been reported to decrease the risk of late-onset hypoglycemia during the recovery period ( $1 \%$ of the time in the 12 -h following PA). In terms of post-HIE hyperglycemia, Aronson et al. (55) reported that a 100 to $150 \%$ correction bolus implemented just after PA sessions and based on the individual's insulin correction factor (how much one unit of rapid or regular insulin will lower blood glucose) was effective at reducing plasma glucose levels without increasing the risk of delayed onset hypoglycemia. 
Overall, for high intensity PA (e.g. high intensity aerobic, interval and, resistance training), it would be suitable to propose less or no insulin BRR as well as less $\mathrm{CHO}$ consumption as compared to those recommended for continuous moderate PA. Therefore, it would be valuable to suspend the insulin delivery or reduce insulin basal rate by $50 \%$ at exercise onset for these types of PA. However, the risk of PA-induced late-onset hypoglycemia should be monitored after all types of PA.

\section{Strategies to reduce PA-induced late-onset hypoglycemia in T1D}

PA per se can increase muscle glucose uptake during and early post-exercise (2-3h) due to increased GLUT-4 and the working muscles' energy demand raising the risk of early hypoglycemia. Moreover, the enhanced insulin sensitivity, also seen early on, remains pronounced for up to 31-h post-exercise, which combined with the need to replenish muscle and liver glycogen stores, increases the risk of late-onset or nocturnal hypoglycemia $(11,56)$. Therefore, applying one or a combination of the strategies described previously may be appropriate to prevent hypoglycemia during PA, but might be insufficient to reduce or avoid post-PA-hypoglycemia. Here, we will review the existing strategies available to prevent post-PA nocturnal hypoglycemia.

Limited evidence-based data is available to mitigate post-PA hypoglycemia. The current proposed strategies are often supported by a single publication and include:

- PA timing: Gomez and colleagues (57) reported that practicing PA in the morning rather than in the afternoon resulted in a significantly reduced risk of late-onset hypoglycemia and was associated with improved metabolic control the next day.

- Qualitative CHO modifications: consuming low-glycemic index (LGI) snacks 1-h pre-PA and 180-min post-PA was found to be protective against hypoglycemia for approximately 8-h, but was insufficient to prevent the risk of nocturnal hypoglycemia beyond this timeframe (58).

- Increased CHO intake: the consumption of whole milk or sports drinks containing CHO before, during and after MOD also reduced the risk of post-PA hypoglycemia, but did not prevent late-onset nocturnal hypoglycemia events (59). As reviewed by Desjardins et al. (60) evidence for the benefit of bedtime snacks to prevent nocturnal hypoglycemia is low, but supported by some data after a PA session.

- Insulin reduction combined with qualitative and quantitative CHO intake: In Campbell et al. (61), participants reduced their basal insulin by $20 \%$ in the morning before performing late afternoon exercise. One hour before PA-onset, a regular CHO meal was consumed, and one-hour post-exercise LGI meal (glycemic index: 37 for LGI vs. 92 for high 
glycemic index meal) was ingested. Both were combined with an insulin bolus reduction (75\% reduction and $50 \%$ reduction, respectively) and then consumed a late-night LGI snack without insulin bolus. Authors reported that this combination effectively reduced the risk of hypoglycemia during and 24-h following the exercise without increasing the risk of hyperglycemia.

- $\quad$ All of the strategies above can be used by individuals with T1D using CSII or MDI. However, for those using CSII, insulin BRR is also an option following PA. Taplin et al. (62) indicated that the combination of CSII suspension during prolonged MOD sessions followed by a $20 \%$ BRR for 6 -h (from 21:00 to 3:00) does effectively reduce the risk of post-PA nocturnal hypoglycemia. Another study found that a pump suspension during MOD or HIE exercise followed by a $20 \%$ BRR during 4-h of early recovery significantly limited the risk of hypoglycemia during and the following hours after exercise. Authors also reported a slightly increased risk of hyperglycemia with HIE (48). Moreover, for the meal following the exercise session a $25 \%$ meal bolus reduction followed by a bedtime snack with or without bolus and associated with a $20 \%$ insulin BRR for 6-h also effectively reduces the risk of nocturnal hypoglycemia (16).

Overall, reducing insulin basal rate by $20 \%$ in the early night (e.g. up to 3 AM) for approximately 6-h and/or consuming a post-exercise snack as well as a bedtime snack with prudent or without insulin doses to prevent lateonset post-exercise hypoglycemia appear to be efficient options for MOD. However, no studies have investigated insulin basal rate reductions in the early evening to prevent late-onset hypoglycemia after practicing high intensity PA. 


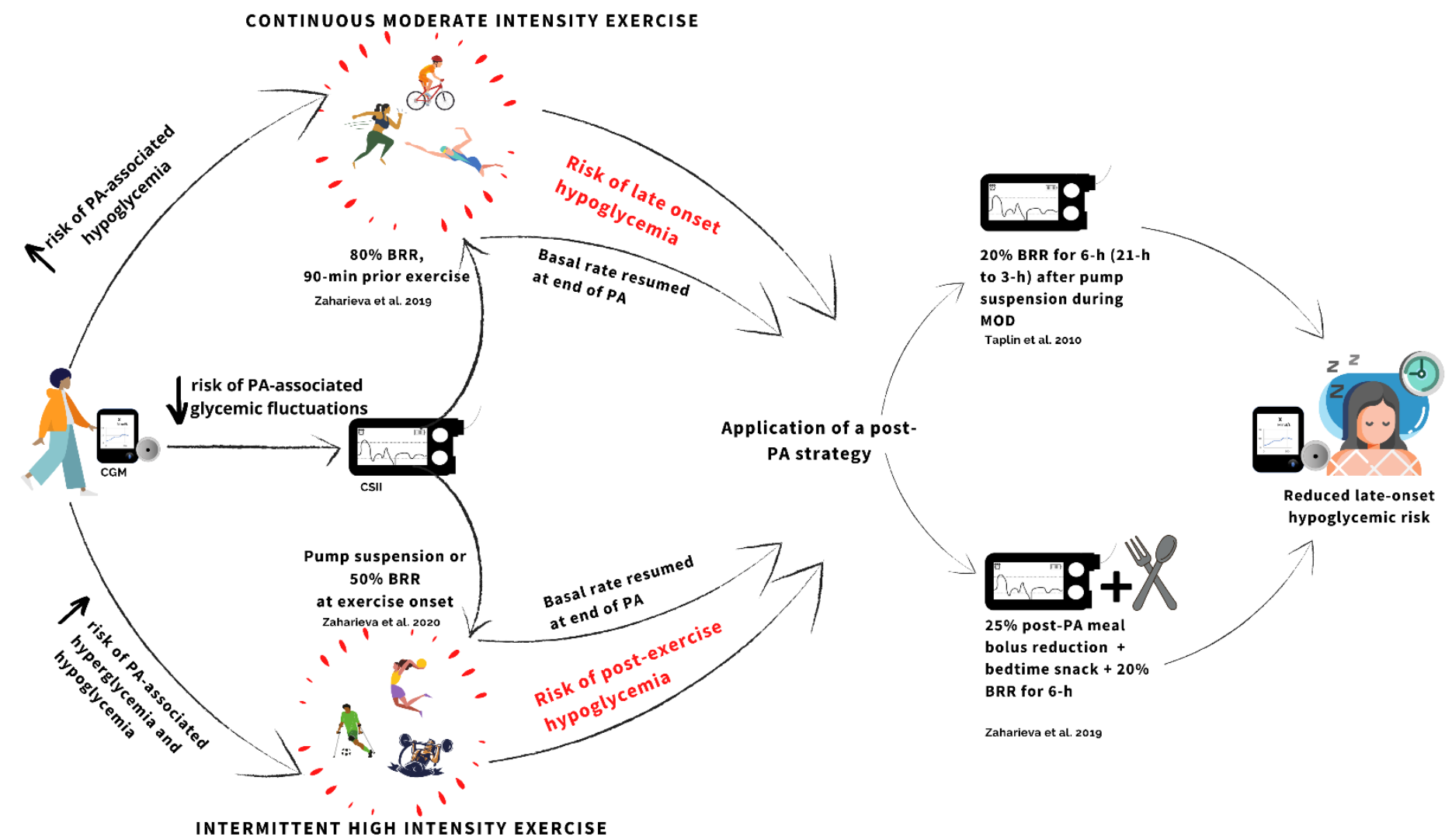

Figure 3 Insulin BRR strategies during and post exercise

CSII provides the flexibility of adjusting insulin basal rates and boluses according to people's specific needs around exercise. In the past 20 years, the combination of real-time continuous glucose monitoring (CGM) with CSII, has had a great impact on facilitating glucose profiling and helping with diabetes management $(66,67)$. Tagougui et al. (65) reported that the use of the CGM around PA improves glucose management during and after PA in individuals with T1D. However, people living with T1D need to be educated about the lower accuracy of these devices during exercise (65).

In this respect, technological advances such as the artificial pancreas, combining CGM and CSII and predictive suspend algorithms have been developed over the past decade. Several studies have evaluated artificial pancreas systems with these specific algorithms during PA $(15,66,67)$. As of now, two artificial pancreas systems are being developed: single-hormone artificial pancreas delivering insulin, and dual hormone artificial pancreas delivering glucagon and insulin. Several studies have compared the efficacy of artificial pancreas systems with usual CSII and reported overall improved glucose control with significantly more time spent within the glycemic target range (68). Recent studies looking at the addition of glucagon found that the dual hormone artificial pancreas seems to be a more efficient method to maintain normoglycemia than the singlehormone artificial pancreas system $(69,70)$. Importantly, a more recent study reported that combining the exercise 
announcement to the single-hormone artificial pancreas system at mealtime with a $33 \%$ bolus reduction was an adequate strategy to mitigate most of the hypoglycemic risk related to aerobic exercise performed during the post-prandial period (71). This study suggests that even in the context of artificial pancreas glucose control some anticipation might be necessary to mitigate exercise-induced glucose fluctuations. Integrating $\mathrm{CHO}$ counting or $\mathrm{CHO}$ ratio learning algorithms to the artificial pancreas systems could be an efficient tool to help people with T1D maintain glycemic target levels. However, to our knowledge, no study has shown significant effects on glucose variations with this kind of algorithm $(72,73)$.

\section{Conclusions}

Regular PA is associated with a wide range of proven and potential benefits in individuals living with T1D. However, PA-induced blood glucose fluctuations, mainly hypoglycemia, frequently occur during and after PA in this population, highlighting the need to provide better recommendations to overcome these adverse events. In order to avoid PA-related glycemic events, people with T1D need to combine a wide variety of insulin reduction and/or increase CHO intake strategies before, during and after PA. It is necessary to consider key factors such as PA type, intensity, duration, timing of the day, relation with food intake as well as active insulin. The hypoglycemic risk and insulin implement specific to the individual, as well as possible mitigation strategies such as CGM/Flash glucose monitor (FGM), should be considered as well. CSII provides greater flexibility to implement insulin strategies and could thus favor a more active lifestyle. Based on current evidence for continuous moderate intensity PA, an $80 \%$ BRR, performed 90-min prior to PA might be an effective strategy to reduce hypoglycemia (16). For intense, high intensity intermittent exercise or resistance exercise, a CSII suspension or a $50 \%$ BRR at PA onset could be sufficient $(17,54)$. Less data is available on how to prevent late-onset hypoglycemic risk but a 20 to $25 \%$ BRR for 6-h in early night hours seems to provide some protection $(16,62)$. Adjusting PA time, duration, and intensity requires a lot of trial and error to individualize the strategy or the combination of approaches to prevent PA-associated hypoglycemia. Emerging use of CSII in the context of artificial pancreas systems could further minimize blood glucose fluctuations associated with PA and thus, reduce the burden of people living with T1D.

Acknowledgements: This work was supported by the JA-DeSève and Lamarre Gosselin research chairs awarded to RRL. ST was supported by CMDO "Réseau de recherche en santé cardiométabolique, diabète et obésité ". NT was supported by a scholarship from the scholarships of Canadian Institutes of Health Research and Fonds de Recherche Santé du Québec.

\section{Conflict of interest:}


RRL has received research grants from the Canadian Diabetes Association, Astra-Zeneca, Eli Lilly, Cystic Fibrosis Canada, Merck, Novo-Nordisk, and Sanofi-Aventis. He has been a consultant or member of advisory panels of Abbott, Amgen, Astra- Zeneca, Boehringer, Carlina Technology, Eli Lilly, Janssen, Medtronic, Merck, Neomed, Novo-Nordisk, Roche, Sanofi-Aventis, and Takeda. He has received honoraria for conferences by Abbott, Astra-Zeneca, Eli Lilly, Janssen, Medtronic, Merck, Novo-Nordisk, and Sanofi-Aventis. He has received in kind contributions related to closed-loop technology from Animas, Medtronic, and Roche. He also benefits from unrestricted grants for clinical and educational activities from Eli Lilly, Lifescan, Medtronic, Merck, Novo Nordisk, and Sanofi. He holds intellectual property in the field of type 2 diabetes risk biomarkers, catheter life and the closed-loop system. He received purchase fee Lilly in relation with closed-loop technology. The remaining authors declare that there are no relationships or activities that might bias, or be perceived to bias, their work.

Table 1 Recommendations for the reduction of pre-meal insulin bolus depending on the duration and intensity of PA (RabasaLhoret et al., 2001)

\begin{tabular}{|c|c|c|c|c|}
\hline & \multirow[t]{2}{*}{ PA duration } & \multicolumn{3}{|c|}{ PA intensity $\left(\% \mathrm{VO}_{2 \max }\right)$} \\
\hline & & $25 \%$ & $50 \%$ & $75 \%$ \\
\hline \multirow{2}{*}{$\begin{array}{l}\text { Dose of meal bolus } \\
\text { reduction (\%) }\end{array}$} & 30-min & 25 & 50 & 75 \\
\hline & 60-min & 30 & 75 & $\varnothing$ \\
\hline
\end{tabular}




\begin{tabular}{|c|c|c|c|c|c|c|}
\hline Authors & Study population & Strategies & PA description & $\frac{\text { Main outcomes }}{\text { during exercise }}$ & $\begin{array}{l}\text { Outcomes during } \\
\text { early recovery }\end{array}$ & $\begin{array}{l}\text { Outcomes during late } \\
\text { recovery }\end{array}$ \\
\hline \multicolumn{7}{|c|}{ PA without anticipation } \\
\hline $\begin{array}{l}\text { Diabetes Research in } \\
\text { Children Network } \\
\text { (DirecNet) Study } \\
\text { Group, } 2006 \\
\text { Diabetes Care }\end{array}$ & $\begin{array}{l}\mathrm{N}=49 \text { children } \\
\text { Mean } A 1_{c}: 7.5 \pm 0.9 \\
\%\end{array}$ & $\begin{array}{l}\text { Insulin pump suspension } \\
\text { (PS) at PA onset } \\
\text { Or Insulin pump } \\
\text { continued } \\
\text { Basal rate was resumed } \\
\text { after } 45-\text { min of } \\
\text { recovery }\end{array}$ & $\begin{array}{l}\text { 75-min moderate } \\
\text { intensity PA }(15 \text {-min } \\
\text { walking at } 55 \% \mathrm{VO}_{2 \max } \\
\text { interspersed with } 5 \text {-min } \\
\text { resting periods, cycle } \\
\text { repeated three times) } \\
\text { Timing of PA: } \approx 4 \text {-h post- } \\
\text { meal }\end{array}$ & $\begin{array}{l}\downarrow \mathrm{BG}^{1} \text { drop with PS }(2.4 \pm 2.1 \\
\mathrm{mmol} / \mathrm{L} \text { vs. } 3.5 \pm 1.8 \mathrm{mmol} / \mathrm{L} \text { with } \\
\text { pump continued) } \\
\text { Frequency of hypoglycemia with PS } \\
<\text { Pump continued ( } 16 \% \text { vs. } 43 \% \\
\text { respectively, } \mathrm{p}=0.003 \text { ) }\end{array}$ & $\begin{array}{l}4 \text { hypoglycemic } \\
\text { events within the } 45- \\
\text { min of recovery with } \\
\text { pump continued }\end{array}$ & No data \\
\hline $\begin{array}{l}\text { Dovc et al. } 2017 \\
\text { Diabetologia }\end{array}$ & $\begin{array}{l}\mathrm{N}=20 \text { children } \\
\text { Mean } A 1_{c}: 7.7 \pm 0.6 \\
\%\end{array}$ & $\begin{array}{l}\text { Insulin pump } \\
\text { suspension } \\
\text { Or Closed loop system } \\
\text { with unannounced PA } \\
\text { Basal rate was } \\
\text { resumed after 4-h of } \\
\text { recovery }\end{array}$ & $\begin{array}{l}\text { 40-min, continuous } \\
\text { moderate intensity PA } \\
(55 \% \mathrm{VO} 2 \mathrm{max}) \\
40 \text {-min, continuous } \\
\text { moderate intensity PA } \\
\left(55 \% \mathrm{VO}_{2 \mathrm{max}}\right) \\
\text { interspersed with } 20-\mathrm{s} \\
\text { sprints }(80 \% \mathrm{VO} 2 \mathrm{max}) \\
\text { every } 6-10-\mathrm{min}(\mathrm{HIE}) \\
\text { Timing of PA: } \approx 3.5-\mathrm{h} \\
\text { post-meal }\end{array}$ & $\begin{array}{l}\text { Limited time spent in hypoglycemia } \\
\text { during PA for both types of PA and } \\
\text { both PS and closed-loop systems } \\
\text { Less time spent in hyperglycemia } \\
\text { with continuous PA ( } 0.0 \% \text { vs. } 1.1 \% \\
\text { with HIE) }\end{array}$ & $\begin{array}{l}\text { Limited time spent in } \\
\text { hypoglycemia the 4-h } \\
\text { after PA for both } \\
\text { types of P and both } \\
\text { PS and closed-loop } \\
\text { systems }\end{array}$ & $\begin{array}{l}\text { Few hypoglycemic events } \\
\text { overnight with PS or } \\
\text { closed loop ( } 4 \text { vs. } 3 \text {, } \\
\text { respectively) }\end{array}$ \\
\hline $\begin{array}{l}\text { Admon et al. } 2005 \\
\text { Pediatrics }\end{array}$ & $\begin{array}{l}\mathrm{N}=10 \text { children } \\
\text { Mean } A 1_{c}: 8.1 \pm 0.8 \\
\%\end{array}$ & $\begin{array}{l}\text { Pump suspension } \\
\text { Or 50\% BRR } \\
\text { Basal rate was } \\
\text { resumed after end of } \\
\text { PA }\end{array}$ & $\begin{array}{l}40-45-\text { min, moderate } \\
\text { intensity PA }\left(60 \% \mathrm{VO}_{2 \max }\right) \\
\text { Timing of PA: } 2 \text {-h post- } \\
\text { meal }\end{array}$ & $\begin{array}{l}\text { No difference in BG } \downarrow \text { during PA } \\
\text { with PS or BRR }(-3.3 \pm 3.2 \mathrm{mmol} / \mathrm{L} \\
\text { vs. }-4.1 \pm 2.8 \mathrm{mmol} / \mathrm{L} \text { with } \mathrm{BRR} \text {, } \\
\mathrm{p}=0.48) \\
\text { No difference in the number of } \\
\text { hypoglycemic events between the } \\
\text { strategies } \\
\text { Hypoglycemic events occurred } \\
\text { within } 20 \text { to } 30 \text {-min of the PA } \\
\text { session }\end{array}$ & No specific data & $\begin{array}{l}\text { No difference in the } \\
\text { number of late } \\
\text { hypoglycemic events } \\
\text { between the strategies } \\
\text { All subjects had } 1 \text { to } 3 \\
\text { late hypoglycemic events } \\
\text { regardless of the strategy }\end{array}$ \\
\hline
\end{tabular}

\footnotetext{
${ }^{1}$ Blood glucose levels
} 
Rickels et al. 2018

Diabetes Care
$\mathrm{N}=15$ adults

Mean $A 1_{c}: 6.8 \%$ 5-min prior to PA start: 45 -min continuous

BRR by $50 \%$ vs. oral

glucose tablets $(20 \mathrm{~g}$ at

PA start $+20 \mathrm{~g}$ at 30 -

min of PA) vs. mini-

dose glucagon (MDG)

PA start)

Insulin pump was

resumed at end of PA

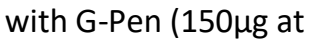

moderate-intensity PA

$\left(50-55 \% \mathrm{VO}_{2 \max }\right)$

Timing of PA: after overnight fasting (at least 8-h)
$B G \downarrow$ with BRR and $\uparrow$ with glucose tablets and MDG during PA (BG at end of PA: $4.7 \pm 1.4$ vs.

$9.7 \pm 3.3$ vs. $8.9 \pm 2.6 \mathrm{mmol} / \mathrm{L}$

respectfully, $\mathrm{p}<.001$ )

Time spent with $\mathrm{BG}<3.8 \mathrm{mmol} / \mathrm{L}$

(\%):

-BRR: $10 \pm 17$

-Glucose tablets: $0 \pm 0$

-MDG: $1 \pm 0$

Time spent with $B G>10 \mathrm{mmol} / \mathrm{L}$

(\%):

-BRR: $1 \pm 4$

-Glucose tablets: $28 \pm 33$

-MDG: $20 \pm 32$

Zaharieva et al. $2017 \quad \mathrm{~N}=12$ adults

Mean $\mathrm{A} 1_{c}: 7.0 \pm 0.9$

$\%$

Insulin pump
suspension at exercise
onset

onset

Basal rate was

resumed at end of PA 40-min, continuous

moderate intensity $\mathrm{PA}$

$\left(40-50 \% \mathrm{VO}_{2 \max }\right)$

40-min, circuit-based PA:

3 series of 13 exercises

Timing of PA: 4-h post-

meal
$\mathrm{BG}^{2} \downarrow$ continuous moderate PA > circuit-based PA (from pre-PA to end of PA: $9.5 \pm 0.7$ to $5.7 \pm 0.4$

$\mathrm{mmol} / \mathrm{L}$ and $8.1 \pm 0.4$ to $6.8 \pm 0.6$

$\mathrm{mmol} / \mathrm{L}$, respectively; $p<0.05$ )
No difference in the

time spent in

hypoglycemia nor

hyperglycemia

between the

strategies
No difference in the time spent in hypoglycemia

nor hyperglycemia between the strategies $\downarrow$ BG variability after $\uparrow$ time spent in circuit-based PA

hypoglycemia (+12-h post-PA) with moderate PA ( $10 \%$ vs. $3 \%$ with circuit-based PA)

\footnotetext{
${ }^{2}$ Blood glucose levels
} 
Zaharieva et al. $2020 \mathrm{~N}=12$ adults

Can J Diabetes
Pump suspension at PA

onset

Or BRR by $50 \%$

Basal rate was

resumed at end of PA 40-min HIE circuit (4-min walk, 45-s marching on

the spot with dumbbells,

60 -s squats with front

sweeps, 4 jumping jacks,

30-s quadruped, 2

jumping jacks, 4 push-

ups, 20-s prone forearm

plank, 4-min cycling at

moderate intensity;

repeated three times)

Timing of PA: $\approx 4$-h post-

meal
No difference in BG variation

during both strategies
No more time spent

in hypoglycemia

during the 12-h

following PA with

$50 \%$ BRR or PS

\begin{tabular}{lll}
\hline Franc et al. 2015 & $\mathrm{~N}=20$ adults & Continuous moderate \\
& Mean $\mathrm{A} 1_{\mathrm{c}}: 7.9 \pm$ & $\mathrm{PA}: \mathrm{BRR}^{3}$ by $50 \%$ or \\
Diabetes Obes. & $0.9 \%$ & $80 \%$ at start of exercise \\
Metab & & $\begin{array}{l}\text { Continuous intense } \\
\text { PA: BRR by } 80 \% \text { or }\end{array}$ \\
& pump suspension at \\
& start of PA \\
& Basal rate was \\
& resumed after 2-h of \\
& recovery
\end{tabular}

30-min, continuous

moderate intensity PA

$\left(50 \% \mathrm{VO}_{2 \mathrm{pic}}\right)$,

30-min, continuous

Intense PA (75\%VO2pic)

Timing of PA: 3-h post-

meal

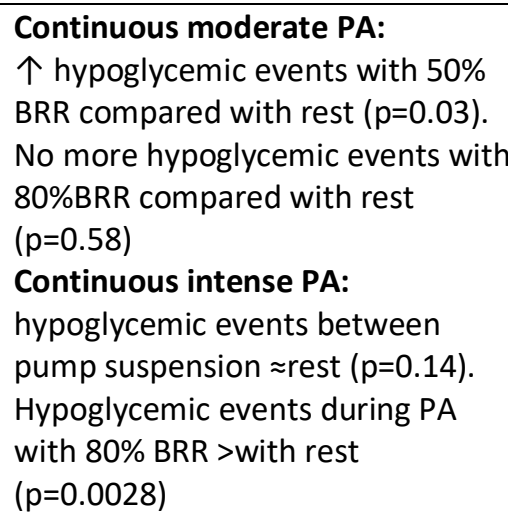

No more hypoglycemic events with

$80 \%$ BRR compared with rest

$(p=0.58)$

Continuous intense PA:

hypoglycemic events between

pump suspension $\approx$ rest ( $p=0.14$ ).

Hypoglycemic events during PA

with $80 \%$ BRR > with rest

$(p=0.0028)$

No data

number of hypoglycemic

events overnight for any

PA session (vs. rest)

\footnotetext{
${ }^{3}$ Basal rate reduction
} 


\begin{tabular}{|c|c|c|c|c|c|c|}
\hline \multicolumn{7}{|c|}{ PA with anticipation } \\
\hline \multicolumn{7}{|c|}{ PA undertaken in the post-absorptive period } \\
\hline $\begin{array}{l}\text { Roy-Fleming } \\
\text { et al. } 2018 \\
\text { Diabetes } \\
\text { Metab }\end{array}$ & $\begin{array}{l}\mathrm{N}=22 \text { adults } \\
\text { Mean } \mathrm{A} 1_{\mathrm{c}} \text { : } \\
56.3 \pm 10.2 \\
\mathrm{mmol} / \mathrm{mol} \\
(7-7,5 \%)\end{array}$ & $\begin{array}{l}\text { 80\% BRR, 40- } \\
\text { min or 20-min } \\
\text { prior to PA vs. } \\
\text { at start of PA } \\
\text { (T0) } \\
\text { No mention of } \\
\text { when basal } \\
\text { rate was } \\
\text { resumed }\end{array}$ & $\begin{array}{l}\text { 45-min moderate } \\
\text { intensity PA at } \\
60 \% \mathrm{VO}_{2 \text { pic }} \\
\text { Timing of PA: 3-h } \\
\text { post-lunch }\end{array}$ & $\begin{array}{l}\text { Time spent in hypoglycemia } \\
\text { was equivalent for either } \\
\text { timing of reduction } \\
\text { ( } \mathrm{p}=0.19 \text { ). } \\
\text { Reducing BRR up to } 40 \text {-min } \\
\text { prior to PA was } \\
\text { insufficient to prevent } \\
\text { hypoglycemia. }\end{array}$ & No data & No data \\
\hline $\begin{array}{l}\text { Zaharieva et } \\
\text { al., } 2019 \\
\text { Diabetes Care }\end{array}$ & $\begin{array}{l}\mathrm{N}=17 \text { adults } \\
\text { Mean } \mathrm{A} 1_{\mathrm{c}} \text { : } \\
6.5 \pm 0.5 \%\end{array}$ & $\begin{array}{l}80 \% \text { or } 50 \% \\
\text { BRR, } 90-\text { min } \\
\text { prior to PA } \\
\text { Or pump } \\
\text { suspension at } \\
\text { PA onset } \\
\text { Basal rate } \\
\text { resumed at } \\
\text { the end of PA } \\
30 \text {-min rest } \\
\text { followed by a } \\
\text { standardized } \\
\text { meal } \\
\text { consumption } \\
\text { with } 25 \% \\
\text { insulin bolus } \\
\text { reduction }\end{array}$ & $\begin{array}{l}\text { 60-min } \\
\text { continuous } \\
\text { moderate } \\
\text { intensity at } 45- \\
55 \% \mathrm{VO}_{2 \text { peak }} \\
\text { Timing of PA: } \approx 3 \text { - } \\
\text { h post-lunch }\end{array}$ & $\begin{array}{l}\text { Less } \downarrow \text { in BG with } 80 \% \text { (T- } \\
90 \text { ) compared with the } \\
\text { other strategies (-1.7 } \pm \\
3.2 \text { vs. }-2.6 \pm 2.8 \mathrm{mmol} / \mathrm{L} \\
\text { with } 50 \% \text { BRR and } 3.7 \pm \\
2.3 \text { mmol/L with PS) } \\
\text { Hypoglycemic events: } 1 \\
\text { with } 80 \% \text { BRR and } \\
\text { with50\%BRR, } 7 \text { with PS } \\
\text { BRR set } 90 \text { min pre-PA may } \\
\text { decreases hypoglycemia } \\
\text { risk during PA better than } \\
\text { PS. }\end{array}$ & & $\begin{array}{l}\text { A post-PA } \\
\text { strategy was } \\
\text { tested to } \\
\text { prevent late } \\
\text { onset } \\
\text { hypoglycemia. }\end{array}$ \\
\hline
\end{tabular}




\begin{tabular}{|c|c|c|c|c|c|c|}
\hline $\begin{array}{l}\text { McAuley et } \\
\text { al. } 2016 \\
\text { Diabetologia }\end{array}$ & $\begin{array}{c}\mathrm{n}=14 \text { adults } \\
\text { Mean } \mathrm{A} 1_{\mathrm{c}} \text { : } \\
7.2 \pm 0.5\end{array}$ & $\begin{array}{l}50 \% \text { BRR, 60- } \\
\text { min prior to } \\
\text { PA }\end{array}$ & $\begin{array}{l}\text { 30-min moderate } \\
\text { intensity PA or } \\
\text { rest } \\
\text { Timing of PA: no } \\
\text { data }\end{array}$ & $\begin{array}{l}\text { During exercise, } 3 \\
\text { participants required } \\
\text { glucose supplementation } \\
\text { to prevent/ treat } \\
\text { hypoglycemia (baseline } \\
\text { glucose was } 5.0 \pm 0.1 \\
\text { mmol/L). } \\
\text { BG } \uparrow \text { during PA: }+0.8 \pm 0.2 \\
\text { mg/dL (BG at baseline } 8.4 \\
\pm 0.5 \mathrm{mmol} / \mathrm{L} \text { ) } \\
\text { Circulating free insulin } \\
\text { 个with PA }(+6 \pm 2 \text { pmol/L } \\
\text { after } 15 \mathrm{~min} ;+5 \pm 2 \\
\text { pmol/L after } 30 \mathrm{~min} ; \\
\text { p<0,001) }\end{array}$ & $\begin{array}{l}\text { No } \\
\text { hypoglycem } \\
\text { ia occurred } \\
\text { during the } \\
2-\mathrm{h} \\
\text { following } \\
\text { PA } \\
\text { BG kept } \\
\text { increasing } \\
\text { after } \\
\mathrm{PA}(\mathrm{p}<0.001)\end{array}$ & No data \\
\hline
\end{tabular}

Table 2 Studies evaluating basal insulin reduction strategies to prevent PA induced hypoglycemia among individuals with T1D using CSII 


\section{References:}

1. Gan MJ, Albanese-O'Neill A, Haller MJ. Type 1 Diabetes: Current Concepts in Epidemiology, Pathophysiology, Clinical Care, and Research. Curr Probl Pediatr Adolesc Health Care. 2012 Nov 1;42(10):269-91.

2. Bonato L, Taleb N, Gingras V, Messier V, Gobeil F, Ménard J, et al. Duration of Catheter Use in Patients with Diabetes Using Continuous Subcutaneous Insulin Infusion: A Review. Diabetes Technol Ther. 2018 Jul 1;20(7):506-15.

3. Shetty G, Wolpert H. Insulin pump use in adults with type 1 diabetes--practical issues. Diabetes Technol Ther. 2010 Jun; 12 Suppl 1:S11-16.

4. Colberg SR, Laan R, Dassau E, Kerr D. Physical Activity and Type 1 Diabetes. J Diabetes Sci Technol. 2015 Jan 6;9(3):609-18.

5. Chimen M, Kennedy A, Nirantharakumar K, Pang TT, Andrews R, Narendran P. What are the health benefits of physical activity in type 1 diabetes mellitus? A literature review. Diabetologia. 2012 Mar 1;55(3):542-51.

6. Norris R, Carroll D, Cochrane R. The effects of physical activity and exercise training on psychological stress and well-being in an adolescent population. J Psychosom Res. 1992 Jan;36(1):55-65.

7. Plotnikoff RC, Taylor LM, Wilson PM, Courneya KS, Sigal RJ, Birkett N, et al. Factors Associated with Physical Activity in Canadian Adults with Diabetes. Med Sci Sports Exerc. 2006 Aug;38(8):1526-34.

8. Thomas N, Alder E, Leese G. Barriers to physical activity in patients with diabetes. Postgrad Med J. 2004 May;80(943):287-91.

9. Brazeau A-S, Rabasa-Lhoret R, Strychar I, Mircescu H. Barriers to physical activity among patients with type 1 diabetes. Diabetes Care. 2008 Nov;31(11):2108-9.

10. Younk L, Mikeladze M, Tate D, N Davis S. Exercise-related hypoglycemia in diabetes mellitus. Expert Rev Endocrinol Metab. 2011;93-108.

11. MacDonald MJ. Postexercise Late-Onset Hypoglycemia in Insulin-Dependent Diabetic Patients. Diabetes Care. 1987 Sep $1 ; 10(5): 584-8$

12. Sandoval DA, Guy DLA, Richardson MA, Ertl AC, Davis SN. Acute, same-day effects of antecedent exercise on counterregulatory responses to subsequent hypoglycemia in type 1 diabetes mellitus. Am J Physiol Endocrinol Metab. 2006 Jun;290(6):E1331-1338.

13. Yardley JE, Kenny GP, Perkins BA, Riddell MC, Balaa N, Malcolm J, et al. Resistance Versus Aerobic Exercise: Acute effects on glycemia in type 1 diabetes. Diabetes Care. 2013 Mar 1;36(3):537-42.

14. Riddell MC, Gallen IW, Smart CE, Taplin CE, Adolfsson P, Lumb AN, et al. Exercise management in type 1 diabetes: a consensus statement. Lancet Diabetes Endocrinol. 2017 May 1;5(5):377-90.

15. Tagougui S, Taleb N, Molvau J, Nguyen É, Raffray M, Rabasa-Lhoret R. Artificial Pancreas Systems and Physical Activity in Patients with Type 1 Diabetes: Challenges, Adopted Approaches, and Future Perspectives. J Diabetes Sci Technol. 2019 Nov;13(6):1077-90.

16. Zaharieva DP, McGaugh S, Pooni R, Vienneau T, Ly T, Riddell MC. Improved Open-Loop Glucose Control With Basal Insulin Reduction 90 Minutes Before Aerobic Exercise in Patients With Type 1 Diabetes on Continuous Subcutaneous Insulin Infusion. Diabetes Care. 2019;42(5):824-31. 
17. Zaharieva DP, Cinar A, Yavelberg L, Jamnik V, Riddell MC. No Disadvantage to Insulin Pump Off vs Pump On During Intermittent High-Intensity Exercise in Adults With Type 1 Diabetes. Can J Diabetes. 2020 Mar 1;44(2):162-8.

18. Tagougui S, Taleb N, Rabasa-Lhoret R. The benefits and limits of technological advances in glucose management around physical activity in patients type 1 diabetes. Front Endocrinol. 2018;

19. Rempel M, Yardley JE, Maclntosh A, Hay JL, Bouchard D, Cornish S, et al. Vigorous Intervals and Hypoglycemia in Type 1 Diabetes: A Randomized Cross Over Trial. Sci Rep. 2018 Oct 26;8(1):15879.

20. Schultes B, Jauch-Chara K, Gais S, Hallschmid M, Reiprich E, Kern W, et al. Defective Awakening Response to Nocturnal Hypoglycemia in Patients with Type 1 Diabetes Mellitus. PLoS Med. 2007 Feb;4(2).

21. Sprague JE, Arbeláez AM. Glucose Counterregulatory Responses to Hypoglycemia. Pediatr Endocrinol Rev PER. 2011 Sep;9(1):46375.

22. Riddell MC, Perkins BA. Type 1 Diabetes and Vigorous Exercise: Applications of Exercise Physiology to Patient Management. Can J Diabetes. 2006 Jan 1;30(1):63-71.

23. Basu R, Johnson ML, Kudva YC, Basu A. Exercise, Hypoglycemia, and Type 1 Diabetes. Diabetes Technol Ther. 2014 May 8;16(6):331-7.

24. Galassetti P, Riddell MC. Exercise and Type 1 Diabetes (T1DM). In: Comprehensive Physiology. American Cancer Society; 2013. p. 1309-36.

25. Christensen NJ, Galbo H. Sympathetic nervous activity during exercise. Annu Rev Physiol. 1983;45:139-53.

26. Borghouts LB, Keizer HA. Exercise and insulin sensitivity: a review. Int J Sports Med. 2000 Jan;21(1):1-12.

27. Bally L, Laimer M, Stettler C. Exercise-associated glucose metabolism in individuals with type 1 diabetes mellitus. Curr Opin Clin Nutr Metab Care. 2015 Jul;18(4):428-33.

28. Ben Brahim N, Place J, Renard E, Breton MD. Identification of Main Factors Explaining Glucose Dynamics During and Immediately After Moderate Exercise in Patients With Type 1 Diabetes. J Diabetes Sci Technol. 2015 Oct 18;9(6):1185-91.

29. Sandoval DA, Guy DLA, Richardson MA, Ertl AC, Davis SN. Effects of Low and Moderate Antecedent Exercise on Counterregulatory Responses to Subsequent Hypoglycemia in Type 1 Diabetes. Diabetes. 2004 Jul 1;53(7):1798-806.

30. Sigal RJ, Armstrong MJ, Bacon SL, Boulé NG, Dasgupta K, Kenny GP, et al. Physical Activity and Diabetes. Can J Diabetes. 2018 Apr;42:S54-63.

31. Davey RJ, Howe W, Paramalingam N, Ferreira LD, Davis EA, Fournier PA, et al. The effect of midday moderate-intensity exercise on postexercise hypoglycemia risk in individuals with type 1 diabetes. J Clin Endocrinol Metab. 2013 Jul;98(7):2908-14.

32. Riddell MC, Zaharieva DP, Tansey M, Tsalikian E, Admon G, Li Z, et al. Individual glucose responses to prolonged moderate intensity aerobic exercise in adolescents with type 1 diabetes: The higher they start, the harder they fall. Pediatr Diabetes. 2019;20(1):99-106.

33. Roy-Fleming A, Taleb N, Messier V, Suppère C, Cameli C, Elbekri S, et al. Timing of insulin basal rate reduction to reduce hypoglycemia during late post-prandial exercise in adults with type 1 diabetes using insulin pump therapy: A randomized crossover trial. Diabetes Metab. 2018 Aug 27;

34. Bally L, Zueger T, Buehler T, Dokumaci AS, Speck C, Pasi N, et al. Metabolic and hormonal response to intermittent high-intensity and continuous moderate intensity exercise in individuals with type 1 diabetes: a randomised crossover study. Diabetologia. 2016 Apr 1;59(4):776-84. 
35. Guelfi, Ratnam N, Smythe GA, Jones TW, Fournier PA. Effect of intermittent high-intensity compared with continuous moderate exercise on glucose production and utilization in individuals with type 1 diabetes. Am J Physiol-Endocrinol Metab. 2007 Mar 1;292(3):E865-70.

36. Codella R, Terruzzi I, Luzi L. Why should people with type 1 diabetes exercise regularly? Acta Diabetol. 2017 Jul 1;54(7):615-30.

37. Kreisman SH, Ah Mew N, Arsenault M, Nessim SJ, Halter JB, Vranic M, et al. Epinephrine infusion during moderate intensity exercise increases glucose production and uptake. Am J Physiol Endocrinol Metab. 2000 May;278(5):E949-957.

38. Marliss EB, Vranic M. Intense exercise has unique effects on both insulin release and its roles in glucoregulation: implications for diabetes. Diabetes. 2002 Feb;51 Suppl 1:S271-283.

39. Bussau VA, Ferreira LD, Jones TW, Fournier PA. The 10-s Maximal Sprint: A novel approach to counter an exercise-mediated fall in glycemia in individuals with type 1 diabetes. Diabetes Care. 2006 Mar 1;29(3):601-6.

40. Lisle DK, Trojian TH. Managing the athlete with type 1 diabetes. Curr Sports Med Rep. 2006 Mar 1;5(2):93-8.

41. Diabetes Research in Children Network (DirecNet) Study Group, Tsalikian E, Kollman C, Tamborlane WB, Beck RW, Fiallo-Scharer R, et al. Prevention of hypoglycemia during exercise in children with type 1 diabetes by suspending basal insulin. Diabetes Care. 2006 Oct;29(10):2200-4.

42. Franc S, Daoudi A, Pochat A, Petit M-H, Randazzo C, Petit C, et al. Insulin-based strategies to prevent hypoglycaemia during and after exercise in adult patients with type 1 diabetes on pump therapy: the DIABRASPORT randomized study. Diabetes Obes Metab. 2015 Dec;17(12):1150-7.

43. Admon G, Weinstein Y, Falk B, Weintrob N, Benzaquen H, Ofan R, et al. Exercise With and Without an Insulin Pump Among Children and Adolescents With Type 1 Diabetes Mellitus. Pediatrics. 2005 Sep 1;116(3):e348-55.

44. Rickels MR, DuBose SN, Toschi E, Beck RW, Verdejo AS, Wolpert H, et al. Mini-Dose Glucagon as a Novel Approach to Prevent Exercise-Induced Hypoglycemia in Type 1 Diabetes. Diabetes Care. 2018 Sep 1;41(9):1909-16.

45. Czenczek-Lewandowska E, Leszczak J, Baran J, Weres A, Wyszyńska J, Lewandowski B, et al. Levels of Physical Activity in Children and Adolescents with Type 1 Diabetes in Relation to the Healthy Comparators and to the Method of Insulin Therapy Used. Int J Environ Res Public Health. 2019 Sep;16(18).

46. Dubé M-C, Prud'homme D, Lemieux S, Lavoie C, Weisnagel SJ. Relation between energy intake and glycemic control in physically active young adults with type 1 diabetes. J Sci Med Sport. 2014 Jan;17(1):47-50.

47. Rabasa-Lhoret R, Bourque J, Ducros F, Chiasson J-L. Guidelines for Premeal Insulin Dose Reduction for Postprandial Exercise of Different Intensities and Durations in Type 1 Diabetic Subjects Treated Intensively With a Basal-Bolus Insulin Regimen (UltralenteLispro). Diabetes Care. 2001 Apr 1;24(4):625-30.

48. Dovc K, Macedoni M, Bratina N, Lepej D, Nimri R, Atlas E, et al. Closed-loop glucose control in young people with type 1 diabetes during and after unannounced physical activity: a randomised controlled crossover trial. Diabetologia. 2017 Nov 1;60(11):215767.

49. McAuley SA, Horsburgh JC, Ward GM, La Gerche A, Gooley JL, Jenkins AJ, et al. Insulin pump basal adjustment for exercise in type 1 diabetes: a randomised crossover study. Diabetologia. 2016;59(8):1636-44.

50. Yardley JE, Iscoe KE, Sigal RJ, Kenny GP, Perkins BA, Riddell MC. Insulin pump therapy is associated with less post-exercise hyperglycemia than multiple daily injections: an observational study of physically active type 1 diabetes patients. Diabetes Technol Ther. 2013 Jan;15(1):84-8. 
51. Aronson R, Li A, Brown RE, McGaugh S, Riddell MC. Flexible insulin therapy with a hybrid regimen of insulin degludec and continuous subcutaneous insulin infusion with pump suspension before exercise in physically active adults with type 1 diabetes (FIT Untethered): a single-centre, open-label, proof-of-concept, randomised crossover trial. Lancet Diabetes Endocrinol. 2020;8(6):511-23.

52. Yardley JE, Kenny GP, Perkins BA, Riddell MC, Malcolm J, Boulay P, et al. Effects of performing resistance exercise before versus after aerobic exercise on glycemia in type 1 diabetes. Diabetes Care. 2012 Apr;35(4):669-75.

53. Reddy R, Wittenberg A, Castle JR, El Youssef J, Winters-Stone K, Gillingham M, et al. Effect of Aerobic and Resistance Exercise on Glycemic Control in Adults With Type 1 Diabetes. Can J Diabetes. 2018 Aug 30;

54. Zaharieva D, Yavelberg L, Jamnik V, Cinar A, Turksoy K, Riddell MC. The Effects of Basal Insulin Suspension at the Start of Exercise on Blood Glucose Levels During Continuous Versus Circuit-Based Exercise in Individuals with Type 1 Diabetes on Continuous Subcutaneous Insulin Infusion. Diabetes Technol Ther. 2017 Jun 1;19(6):370-8.

55. Aronson R, Brown RE, Li A, Riddell MC. Optimal Insulin Correction Factor in Post-High-Intensity Exercise Hyperglycemia in Adults With Type 1 Diabetes: The FIT Study. Diabetes Care. 2019;42(1):10-6.

56. Tsalikian E, Mauras N, Beck RW, Tamborlane WV, Janz KF, Chase HP, et al. Impact of exercise on overnight glycemic control in children with type 1 diabetes mellitus. J Pediatr. 2005 Oct;147(4):528-34.

57. Gomez AM, Gomez C, Aschner P, Veloza A, Muñoz O, Rubio C, et al. Effects of performing morning versus afternoon exercise on glycemic control and hypoglycemia frequency in type 1 diabetes patients on sensor-augmented insulin pump therapy. J Diabetes Sci Technol. 2015 May;9(3):619-24.

58. Campbell MD, Walker M, Trenell MI, Stevenson EJ, Turner D, Bracken RM, et al. A low-glycemic index meal and bedtime snack prevents postprandial hyperglycemia and associated rises in inflammatory markers, providing protection from early but not late nocturnal hypoglycemia following evening exercise in type 1 diabetes. Diabetes Care. 2014 Jul;37(7):1845-53.

59. Hernandez JM, Moccia T, Fluckey JD, Ulbrecht JS, Farrell PA. Fluid snacks to help persons with type 1 diabetes avoid late onset postexercise hypoglycemia. Med Sci Sports Exerc. 2000 May;32(5):904-10.

60. Desjardins K, Brazeau A-S, Strychar I, Rabasa-Lhoret R. Are bedtime nutritional strategies effective in preventing nocturnal hypoglycaemia in patients with type 1 diabetes? Diabetes Obes Metab. 2014;16(7):577-87.

61. Campbell MD, Walker M, Bracken RM, Turner D, Stevenson EJ, Gonzalez JT, et al. Insulin therapy and dietary adjustments to normalize glycemia and prevent nocturnal hypoglycemia after evening exercise in type 1 diabetes: a randomized controlled trial. BMJ Open Diabetes Res Care. 2015 May 1;3(1):e000085.

62. Taplin CE, Cobry E, Messer L, McFann K, Chase HP, Fiallo-Scharer R. Preventing post-exercise nocturnal hypoglycemia in children with type 1 diabetes. J Pediatr. 2010 Nov;157(5):784-788.e1.

63. Battelino T, Conget I, Olsen B, Schütz-Fuhrmann I, Hommel E, Hoogma R, et al. The use and efficacy of continuous glucose monitoring in type 1 diabetes treated with insulin pump therapy: a randomised controlled trial. Diabetologia. 2012 Dec;55(12):3155-62.

64. Poolsup N, Suksomboon N, Kyaw AM. Systematic review and meta-analysis of the effectiveness of continuous glucose monitoring (CGM) on glucose control in diabetes. Diabetol Metab Syndr. 2013 Jul 23;5(1):39.

65. Tagougui S, Taleb N, Rabasa-Lhoret R. The Benefits and Limits of Technological Advances in Glucose Management Around Physical Activity in Patients Type 1 Diabetes. Front Endocrinol. 2018;9:818.

66. Bally L, Thabit H. Closing the Loop on Exercise in Type 1 Diabetes. Curr Diabetes Rev. 2018;14(3):257-65. 
67. Riddell MC, Zaharieva DP, Yavelberg L, Cinar A, Jamnik VK. Exercise and the Development of the Artificial Pancreas: One of the More Difficult Series of Hurdles. J Diabetes Sci Technol. 2015 Oct 1;9(6):1217-26.

68. Bekiari E, Kitsios K, Thabit H, Tauschmann M, Athanasiadou E, Karagiannis T, et al. Artificial pancreas treatment for outpatients with type 1 diabetes: systematic review and meta-analysis. BMJ. 2018 Apr 18;361.

69. Taleb N, Emami A, Suppere C, Messier V, Legault L, Ladouceur M, et al. Efficacy of single-hormone and dual-hormone artificial pancreas during continuous and interval exercise in adult patients with type 1 diabetes: randomised controlled crossover trial. Diabetologia. 2016 Dec 1;59(12):2561-71.

70. Weisman A, Bai J-W, Cardinez M, Kramer CK, Perkins BA. Effect of artificial pancreas systems on glycaemic control in patients with type 1 diabetes: a systematic review and meta-analysis of outpatient randomised controlled trials. Lancet Diabetes Endocrinol. 2017 Jul 1;5(7):501-12.

71. Tagougui S, Taleb N, Legault L, Suppere C, Messier V, Boukabous I, et al. Single-blind, randomised, crossover study to reduce hypoglycaemia risk during postprandial exercise with closed-loop insulin delivery in adults with type 1 diabetes: announced (with or without bolus reduction) vs unannounced exercise strategies. Diabetologia. 2020;

72. Gingras V, Rabasa-Lhoret R, Messier V, Ladouceur M, Legault L, Haidar A. Efficacy of dual-hormone artificial pancreas to alleviate the carbohydrate-counting burden of type 1 diabetes: A randomized crossover trial. Diabetes Metab. 2016 Feb 1;42(1):47-54.

73. Palisaitis E, El Fathi A, Von Oettingen JE, Krishnamoorthy P, Kearney R, Jacobs P, et al. The Efficacy of Basal Rate and Carbohydrate Ratio Learning Algorithm for Closed-Loop Insulin Delivery (Artificial Pancreas) in Youth with Type 1 Diabetes in a Diabetes Camp. Diabetes Technol Ther. 2020;22(3):185-94. 